\title{
Una reconciliación frustrada y su superación*
}

\author{
Juan Hernández Pico, S.J., \\ Centro de Reflexión Teológica, \\ San Salvador
}

¿Por qué, casi 20 años después de la firma de los acuerdos de paz, no nos hemos acercado a la reconciliación en El Salvador y cómo superaremos este impasse?

Creo que hay que buscar las causas, al menos, en cinco niveles socioteológicos. Y luego, proponer la comprensión teológicamente cristiana de la reconciliación (intellectus reconciliationis) y el camino hacia ella a partir de la profundización de esos niveles de la realidad nacional.

\section{Firmar la paz no es lo mismo que reconciliar las voluntades}

La primera causa la encontramos en la introducción al mismo informe de la Comisión de la Verdad. En De la locura a la esperanza, el 15 de marzo de 1993, la Comisión de la Verdad de las Naciones Unidas afirma que entre 1980 y 1991, "la República de El Salvador (...) estuvo sumida en una guerra que hundió a la sociedad salvadoreña en la violencia, le dejó millares y millares de muertos, y la marcó con formas delincuenciales de espanto; hasta el 16 de enero de 1992, en que las voluntades reconciliadas firmaron la paz en el Castillo de Chapultepec, en México, e hicieron brillar de nuevo la luz para pasar de la locura a la esperanza" (cursivas mías).

En este breve párrafo se encierra un grave malentendido: que la firma de la paz implicaba ya la reconciliación de las voluntades. La firma de la paz era más bien el resultado del reconocimiento mutuo de que ninguna de las partes beligerantes podía ganar la guerra militarmente. Se imponía, pues, un final del conflicto en forma de acuerdos de paz, producto de negociaciones difíciles en que cada contendiente pretendía perder lo menos y ganar lo más posible. Pero

* Cátedra de Realidad Nacional, 10 de noviembre de 2011. 
eso no significaba necesariamente la reconciliación de las voluntades que se habían enfrentado en la guerra. Y tampoco significaba la reconciliación mutua sobre bases de verdad, justicia y perdón entre las grandes mayorías del pueblo salvadoreño y las minorías privilegiadas. Es notable que el mismo informe piense que "la necesidad de ponerse de acuerdo sobre una Comisión de la Verdad, brota del reconocimiento de las partes sobre el desplome del comunismo que alentaba a una de ellas, y acaso de la desilusión de la potencia que alentaba a la otra". Es decir, de factores que contribuían a hacer imposible cualquier triunfo militar.

El final de la guerra no coincide históricamente con el logro de la reconciliación. Porque la paz no es solo la ausencia de la guerra, sino principalmente la prosperidad del pueblo, una prosperidad lanzada sobre todo por una capaz e incorrupta administración del potencial de desarrollo de un país que privilegiará especialmente a los pobres. Esa es bíblicamente la misión del gobernante justo: "Oh, Dios, confía tu juicio al rey, y tu rectitud al hijo del rey. Para que gobierne a tu pueblo con justicia, a tus humildes con rectitud”. ¿Y cuál será el efecto de este gobierno justo? Será la prosperidad propia de esa paz con justicia: "Produzcan los montes bienestar y las colinas prosperidad para tu pueblo; que él defienda a los humildes del pueblo, socorra a los hijos de los pobres y aplaste al opresor" (Sal 72, 1-4). Cuando la política y los funcionarios del Estado, ejecutivos, legisladores y jueces, actúen así y así salgan al encuentro de las aspiraciones de la gente, entonces avanzaremos hacia la paz que puede conllevar reconciliación.

Así pues, el primer nivel del retraso de la reconciliación en El Salvador es la falta de distinción entre la firma de la paz y la reconciliación. Cuando esta distinción no se hace, se produce un grave desequilibrio: no se concede a la reconciliación el carácter de proceso que caracterizó a la firma de la paz. La paz contenida en la firma de los acuerdos fue el final de un proceso de negociaciones para detener y terminar la guerra y fue también el diseño de un proyecto renovado de convivencia ciudadana, aunque el diseño de nueva convivencia fue de menor calado que los acuerdos para terminar la guerra. Acercar la reconciliación ha de implicar también retomar ese proyecto y llevarlo hasta el final, por medio de un proceso de encuentros humanos para revertir la hostilidad entre la ciudadanía en El Salvador y terminar con su enemistad.

\section{La falta de reconocimiento de la verdad, especialmente del daño causado}

En esa introducción, la Comisión de la Verdad enfatiza que su vocación y su esencia eran la búsqueda, el encuentro y la publicación de esa verdad en los hechos de violencia realizados por tirios y troyanos (cursivas mías). La verdad, toda la verdad y nada más que la verdad (...) La verdad global y la verdad específica. La verdad resplandeciente pero tranquila (...), siempre en el contexto pedagógico de que se contribuya a la reconciliación y a la abolición de aquellos patrones de comportamiento en la nueva sociedad. 
Me parece evidente que muchos de los señalados en el informe de la Comisión de la Verdad como responsables de enormes y brutales violaciones de los derechos humanos y de crímenes de lesa humanidad y contra el derecho humanitario en la guerra, no han reconocido esa verdad y muchas veces la han negado. Y en consecuencia han negado la responsabilidad de los daños causados atribuyéndola únicamente al enemigo. Les faltó esa "honradez con la realidad" que fundamenta la búsqueda y el reconocimiento de la verdad'.

Es innegable que la falta de reconocimiento de la verdad investigada por la Comisión de la Verdad, la falta de reconocimiento de los resultados del informe, e incluso la negación de esa verdad por el entonces presidente Cristiani, por la Fuerza Armada, por la Corte Suprema de Justicia, por el partido Arena y por la Asamblea que decretó la amnistía, lejos de contribuir a la reconciliación la han vuelto más difícil y escabrosa. Cuando la verdad no es reconocida e incluso es negada, la reconciliación se aleja y se producen quiebres y hundimientos en el camino hacia ella. Reconocer la verdad de los resultados contenidos en el informe de la Comisión de la Verdad implica reconocer los daños causados, reconocer que el Estado salvadoreño incurrió durante la guerra en terrorismo de Estado, puesto que cometió hechos criminales no excepcionales sino normales, que se convirtieron en un patrón de conducta criminal violadora de las normas jurídicas de humanidad exigibles a los contendientes también en la guerra: torturas, desaparecimientos, asesinatos, masacres, etc. Los guerrilleros beligerantes reconocieron los hechos a ellos imputados por la Comisión de la Verdad, pero tampoco reconocieron el carácter criminal de estos hechos cometidos durante la guerra, que se convirtieron en normales y no excepcionales: especialmente, los asesinatos y ejecuciones extrajudiciales.

Según la Comisión de la Verdad, el 85\% de las denuncias recibidas sobre estos crímenes fue atribuido por los denunciantes a "agentes del Estado" y solo el 15\% fue atribuido "al FMLN". Cuantitativamente, se trata de una enorme diferencia. Cualitativamente, sin embargo, ambos contendientes están vinculados en la responsabilidad por haber justificado estas atrocidades como defensa de la patria o de la revolución.

Se trata de la justificación de la violencia extramilitar, ajena a los enfrentamientos bélicos. La falta de honradez con la realidad traducida en negación de la verdad tiene graves consecuencias ciudadanas; se vive bajo el imperio del miedo

1. J. Sobrino, Jesucristo liberador. Lectura histórica-teológica de Jesús de Nazaret, San Salvador, UCA Editores, 1991, pp. 29-30. Ver, del mismo autor, "Honradez con lo real", en Terremoto, terrorismo, barbarie y utopía, San Salvador, UCA Editores, 2006, pp. 67-94; y también "El pueblo crucificado y la civilización de la pobreza. El 'Hacerse cargo de la realidad' de Ignacio Ellacuría', en Fuera de los pobres no hay salvación, Madrid, Trotta, pp. 17-38. 
al pueblo y al futuro, se siguen edificando enormes muros para ocultar tras de ellos el lujo de las mansiones, se rodea a estas mansiones de medidas extraordinarias de seguridad que se vuelven ordinarias, se viaja con guardaespaldas por el país, se huye del examen de la constitucionalidad o inconstitucionalidad de la amnistía, etc. Por eso se vive sin auténtica libertad. Porque la negación de la verdad moral y de la honradez con la realidad conducen a una vida inauténtica. Por eso se buscan muchas veces huidas en ciertos fundamentalismos que abordan los crímenes por medio del así llamado encuentro con Cristo, convirtiendo lo que debiera ser auténtica conversión en un desahogo de la angustia moral.

El Evangelio nos avisa que solo el reconocimiento de la verdad nos hará libres ( $c f r$. Jn 8, 32). Pero historizándolo se trata en concreto de la verdad de los daños causados a las víctimas de la guerra. En El Salvador, ser "honrado con la realidad" y "hacerse cargo" analíticamente de ella fue lo que caracterizó las homilías dominicales de monseñor Romero durante los tres años en que fue pastor de la arquidiócesis. Claro que además él "cargó" éticamente con la realidad salvadoreña, iluminándola fraternalmente con sus valores evangélicos, y "se encargó" de ella mostrando con su profetismo y su amor utópico y esperanzado el camino para empezar a transformarla ${ }^{2}$. Como dice Jon Sobrino, se puede también "ser cargados por la realidad" o "dejarse cargar "3 por ella. Y monseñor Romero es también paradigma de esta vivencia de la gracia solidaria en negativo y en positivo: "A mí me toca ir recogiendo atropellos, cadáveres y todo eso que va dejando la persecución de la Iglesia". O "con este pueblo no cuesta ser buen pastor... Soy simplemente el pastor, el hermano, el amigo de este pueblo, que sabe de sus sufrimientos, de sus hambres, de sus angustias, y en nombre de esas voces yo levanto mi voz"s.

Así pues, el segundo nivel del retraso en el proceso de reconciliación en El Salvador es la falta de reconocimiento de la verdad o incluso su negación por causa de la deshonestidad con la realidad. En tales circunstancias es mucho más complicado avanzar por el camino que conduce a convertir la hostilidad en calma y la enemistad en amistad aun siendo adversarios. Sin reconocimiento de

2. Cf. I. Ellacuría, "Hacia una fundamentación del método teológico latinoamericano", en Escritos teológicos, I, San Salvador, UCA Editores, 2000, pp. 187-218, en especial p. 208.

3. J. Sobrino, Fuera de los pobres no hay salvación. Pequeños ensayos utópico-proféticos, Madrid, Trotta, 2007, p. 18.

4. M. Cavada Díez (ed.), Homilías de monseñor Óscar A. Romero, tomo I, San Salvador, UCA Editores, 2006, p. 149. Ver también M. Cavada, El corazón de monseñor Romero, San Salvador, CMR, UCA, JSC, p. 9.

5. M. Cavada, Homilías de monseñor Óscar A. Romero, tomo V, UCA Editores, p. 542; y tomo VI, UCA Editores, p. 167. Ver también M. Cavada, El corazón de monseñor Romero, op. cit., pp. 71 y 75. 
la verdad es casi imposible la reconciliación. La dificultad de ese reconocimiento consiste en que reconocer la verdad implica ser honrados con la realidad y "hacerse cargo" de que ambas luchas, la estatal y la revolucionaria, estuvieron atravesadas por crímenes contra la humanidad, que nunca pudieron haberse justificado. La verdad requiere honrada humildad, es decir, deponer el orgullo que consiste en la defensa absolutista de una causa. Las causas o banderas por las que se luchó pudieron ser dignas y su defensa, sin embargo, pudo estar atravesada de indignidad. La honradez en reconocerlo hace posible asumir la verdad y caminar hacia la reconciliación.

\section{La justicia que restablece el respeto al derecho}

La Comisión de la Verdad recuerda además que la investigación de la verdad de los hechos está vinculada con acciones de justicia que restablezcan el respeto al derecho y a las leyes que lo encarnan. Se refiere al acuerdo de paz firmado en Chapultepec y recuerda que allá se encomendó a dicha Comisión "la investigación de graves hechos de violencia ocurridos desde 1980, cuya huella sobre la sociedad reclama con mayor urgencia el conocimiento público de la verdad" (art. 2. ${ }^{\circ}$. Continúa recordando que "en el artículo $5 .^{\circ}$ se le asigna el 'esclarecer y superar todo señalamiento de impunidad de oficiales de la Fuerza Armada"'. Y se da una explicación: "Hechos de esa naturaleza, independientemente del sector al que pertenecieron sus autores, deben ser objeto de la actuación ejemplarizante de los tribunales de justicia, a fin de que se apliquen a quienes resulten responsables, las sanciones contempladas por la ley" (cursivas mías).

Estamos, pues, frente al tema de la justicia. La justicia sobre las acciones de los beligerantes ha sido soslayada en los veinte años que nos separan de los Acuerdos de Paz. Pero en nuestra tradición bíblica, sin justicia es imposible la paz. Afirma Isaías lapidariamente: "La paz es efecto de la justicia" (Is 32, 17). Pero cuando se les ha planteado a los presidentes de este país buscar la justicia en el asesinato del arzobispo Romero, uno tras otro han hablado de "perdón y olvido" y de "no reabrir heridas del pasado". Cuando al anterior presidente, Antonio Saca, se le recordaron las recomendaciones de la Comisión Interamericana de Derechos Humanos sobre la necesidad de retomar el proceso sobre el crimen en el que se asesinó a monseñor Romero, alegó que había sido electo "para gobernar hacia el futuro, no hacia el pasado". Con estas palabras han expresado su temor de que cualquier ejercicio de la justicia va a engendrar en El Salvador torbellinos de inquietud y desasosiego, que pueden conducir hacia su desestabilización. Muy distinta es la visión del libro de Isaías, que escribe así a continuación de lo que ya hemos citado: "La función de la justicia [es] calma y tranquilidad perpetuas. Mi pueblo habitará en un lugar pacífico, en moradas tranquilas, en mansiones sosegadas" (Is 32, 17-18). 
Por desgracia, hoy no podemos afirmar sin grandes matices que los Acuerdos de Paz sin ninguna clase de justicia para lo sucedido en la guerra, hayan traído la paz al país. Los índices de violencia están hoy entre los más altos del mundo, si exceptuamos zonas de guerra, como Afganistán, los Grandes Lagos o Sudán (Darfur), en África, por ejemplo. El 27 de octubre de este año (2011) una comisión de la ONU publicó en Ginebra un informe sobre la violencia en el mundo. El Salvador aparece como el país más violento, con una tasa de 62 homicidios por cada 100 mil habitantes. Miembros del Gobierno han afirmado que eso se refiere a lo ocurrido durante la presidencia anterior de Antonio Saca. Sin embargo, sea o no así, es una tasa lo bastante reciente como para abrumarnos por su horror.

Es lamentable que en este país la única justicia con que se ha contado, y que se ha descartado con gran temor, es la justicia penal retributiva, cuyo paradigma fue la drástica justicia de los vencedores en la Segunda Guerra Mundial contra los prisioneros de guerra nazis políticos y militares que se aplicó en Núremberg. Sin embargo, existen situaciones, como las de una transición entre dictaduras represivas y democracias incipientes o restauradas, donde se ha aplicado una forma distinta de justicia, la justicia transicional. De ella hay ejemplos diversos y muy distintos, desde las leyes de punto final, que luego han sido revocadas, y los juicios penales nacionales a los dictadores argentinos, pasando por los juicios penales a los genocidas serbios, serbobosnios y liberianos en la Corte Penal Internacional de La Haya, hasta el pacto del olvido frente a los crímenes de la dictadura militar brasileña.

Existen además otras formas de justicia. En Sudáfrica se dio una situación en cierta manera similar a la salvadoreña. Ni los defensores del apartheid ni los miembros del congreso africano tenían la capacidad de ganar una guerra civil. Se llegó a conversaciones de paz que terminaron con la supresión del apartheid y la sumisión de todos a elecciones democráticas, que cambiaron a los gobernantes, pues el congreso africano superó en ellas a los partidos de base racial blanca minoritaria. Gracias a figuras carismáticas como el arzobispo Desmond Tutu, premio Nobel de la Paz, y el entonces recién electo presidente Nelson Mandela se llegó a crear la Comisión de la Verdad y Reconciliación, en el seno de la cual se aplicó la justicia restaurativa. Esta última considera posible el encuentro interpersonal entre ofensores y víctimas, con efectos profundamente catárticos, que culminan en ciertas formas no penales de reconocimiento y reparación de la ofensa.

En El Salvador, el Instituto de Derechos Humanos de la UCA (IDHUCA) ha intentado la justicia restaurativa ya tres años consecutivos, pero sin haber podido lograr el encuentro entre ofensores y víctimas o personas ofendidas, pues ya hemos dicho que aquí existe un casi absoluto déficit de reconocimiento de los crímenes u ofensas. Aquí la catarsis restaurativa de la justicia se logró únicamente porque los relatos de algunas víctimas o personas ofendidas durante la guerra pudieron ser escuchados por magistrados extranjeros y salvadoreños 
que emitieron sentencias transicionales que otorgaban a las víctimas la razón y les devolvían, con ella, la dignidad humana herida.

Así pues, el tercer nivel del retraso en el proceso de reconciliación en El Salvador es la falta de aplicación de cualquier forma de justicia. En estas circunstancias — repitámoslo_ es mucho más complicado avanzar por el camino que conduce a convertir la hostilidad en paz y la enemistad en convivencia tranquila. Sin aplicación de ninguna clase de justicia para las víctimas es casi imposible la reconciliación. El temor a reconocer la ofensa ha llevado al Estado salvadoreño a negar todo tipo de justicia. Detrás está probablemente la gran dificultad de aceptar que miembros de la Fuerza Armada y prominentes miembros de la sociedad civil —estos últimos bajo la máscara de miembros de los escuadrones de la muerte u organizadores o financiadores de ellos - cometieron en la guerra crímenes de lesa humanidad. El orgullo y la ceguera disfrazados de patriotismo llevaron a la negación de la justicia. Mientras tanto, queda patente que el camino para gobernar hacia el futuro no es olvidar el pasado, sino esforzarse por superarlo sanándolo, y eso no se puede lograr sin alguna forma de justicia.

\section{Encarar la impunidad genérica e institucionalizada}

La Comisión de la Verdad añade en la introducción a su informe que la necesidad de un acuerdo sobre la misma comisión surge también de

la urgencia de encarar el tema de la impunidad genérica e institucionalizada, que (...) ha minado [a la sociedad salvadoreña] en su más íntima entraña, puesto que al amparo de los organismos del Estado pero al margen de la ley se sucedieron violaciones reiterativas de los derechos humanos por integrantes de la Fuerza Armada; y transgresiones de esos mismos derechos por los guerrilleros. (Cursivas mías.)

Ya hemos visto en el punto anterior que la Comisión recordaba que "en el artículo 5. ${ }^{\circ}$ [del acuerdo de paz] se le asigna el 'esclarecer y superar todo señalamiento de impunidad de oficiales de la Fuerza Armada". Y se da una explicación: "Hechos de esa naturaleza, independientemente del sector al que pertenecieron sus autores, deben ser objeto de la actuación ejemplarizante de los tribunales de justicia, a fin de que se apliquen a quienes resulten responsables, las sanciones contempladas por la ley".

Estamos, pues, frente a esa lacra social y política encarnada en la impunidad. Esa impunidad sigue veinte años después minando la "más íntima entraña" de la sociedad salvadoreña. La equivocada equivalencia de la firma de la paz con la reconciliación, la ausencia de reconocimiento de la verdad y la falta de cualquier tipo de justicia afianzan esa impunidad. El resultado es una sociedad que intenta superar la guerra sin sanar sus heridas, situándose así en peligro de provocar una gangrena, una tremenda pudrición del cuerpo social. O, tal vez peor aún, 
provocando la sobrevivencia y perpetuación de un resentimiento irredento que conduce por diversos caminos a la situación de violencia que hoy nos aqueja en El Salvador después de veinte años de la firma de la paz. La impunidad quedó entronizada en el sistema legal salvadoreño cuando la asamblea nacional votó la Ley de Amnistía amplia e incondicional el 20 de marzo de 1993, cinco días después de haber sido publicado el informe De la locura a la esperanza por la Comisión de la Verdad. Es decir, con absoluta aceleración e irreflexión de sus consecuencias.

Así pues, el cuarto nivel del retraso en el proceso de reconciliación en El Salvador es la permanencia de la impunidad. Sin resolver de alguna manera socialmente válida el problema de la impunidad es imposible caminar hacia la reconciliación. Además, si el informe de la Comisión de la Verdad no tenía carácter de obligatoriedad jurídica para el Estado, no se ve por qué la asamblea nacional consideró necesario votar la Ley de Amnistía. Era en realidad una confesión de culpa que pretendía lo que el lenguaje popular conoce como "curarse en salud". Por lo demás, la amnistía no debería haber tenido ninguna aplicación constitucional para los funcionarios públicos civiles o militares del Gobierno de Alfredo Cristiani, respecto de crímenes cometidos durante ese período de gobierno durante el cual se votó la ley. Así lo dice el artículo 224 de la Constitución de El Salvador.

De todas maneras, al decretar esta Ley de Amnistía unilateralmente desde el poder, sin ningún diálogo con las víctimas de los crímenes amnistiados, se iba directamente en contra del proceso de reconciliación. La sombra de aquel acto motivado por el miedo a la realidad desenmascarada en el informe se ha alargado hasta hoy. Lo acabamos de ver en la forma evasiva como la Corte Suprema de Justicia ha tratado las órdenes de detención de los acusados en el asesinato en 1989 de los jesuitas de la UCA emitidas por la Audiencia Nacional de España a través de Interpol. Ya el entonces presidente Cristiani afirmó por su cuenta y riesgo en el mensaje dirigido a la nación, el 18 de marzo de 1993, que "en esta materia del fomento de la reconciliación, consideramos que el informe de la Comisión de la Verdad no responde al anhelo de la mayoría de salvadoreños, que es el perdón y el olvido de todo lo que fue ese pasado tan doloroso, que tanto sufrimiento trajo a la familia salvadoreña". Pasar "una página dolorosa de nuestra historia", como el mismo Cristiani dijo, sin entrar en un proceso humanamente serio y honrado con la realidad, iba a provocar precisamente lo contrario de la reconciliación, como lo muestra el abismo de violencia en el que aún estamos hundidos.

\section{La permanencia en El Salvador de las causas que motivaron la rebelión y la guerra}

5.1. El quinto nivel del retraso en la reconciliación, que no suele ser tocado habitualmente, es la permanencia de una distancia grande entre los pocos ricos y los muchos pobres. Es el escándalo de la enorme desigualdad. Se mide la 
desigualdad en un país por medio del coeficiente de Gini, donde cuanto más cercano está de cero el coeficiente, mayor igualdad hay en un país, y hay mayor desigualdad cuanto más cercano de 100 está el coeficiente. Según el Informe de Desarrollo Humano del PNUD de 2009, el coeficiente de Gini para El Salvador es 49.7. La desigualdad en El Salvador es mucho mayor que en los países escandinavos: alrededor del 25, Dinamarca (24.7), Suecia (25), Noruega (25.8) y Finlandia (26.9). Y entre los países industrializados solo en los Estados Unidos es mayor de 40 (40.8). Por otro lado, en Centroamérica solo Costa Rica tiene una desigualdad menor (47.2) que la de este país. De aquellos países de América Latina de donde tenemos datos, solo Venezuela (43.4), Uruguay (46.2) y México (48.1) son menos desiguales que este país. La gran lacra de los países del continente americano, con la excepción de Canadá (32.6), es su gran desigualdad, destacando a esa fecha Haití (59.5), Colombia (58.5), Bolivia (58.2), Brasil (55) y Guatemala (53.7). Solo en África se dan desigualdades gigantescas, semejantes o mayores que las de América: Sudáfrica (57.8), Botsuana (61) y Namibia (74.3). Pero la comparación de nuestro país con los países escandinavos, los menos desiguales del mundo, es muy pertinente porque todos ellos eran pobres hace cien años, al comienzo del siglo XX, y su enriquecimiento no ha conllevado la apertura de una gran brecha de desigualdad.

5.2. Esta desigualdad se traduce también en el índice de pobreza humana. El Salvador ocupa el puesto 106 entre 182 países en el Índice de Pobreza Humana y de Ingresos, es decir, 15 puestos más abajo de la mitad. Este índice mide las privaciones en las tres dimensiones básicas que componen el índice de desarrollo humano: vida larga y saludable, conocimientos y nivel de vida digno. Es un compuesto que mide la probabilidad al nacer de no vivir hasta los 60 años, el porcentaje de adultos que carecen de aptitudes de alfabetización funcional, el porcentaje de personas que viven por debajo del umbral de pobreza (en El Salvador, el 37.2\%) y la tasa de desempleo a largo plazo. De 1998 a 2009, el país ha avanzado solamente 8 puestos en este índice. En 1998 ocupaba el puesto 114 y hoy el 1067.

5.3. La misma desigualdad admite traducción también en la corriente migratoria hacia los Estados Unidos. En 1989, basado en una encuesta del IUDOP, Segundo Montes calculó que vivían en los Estados Unidos 950,255 personas, mientras que en El Salvador vivían 6,271,087, es decir vivían en Estados Unidos el 15.13\% de los que vivían en El Salvador. En 2000 tanto el total de los que vivían en Estados Unidos como el porcentaje respecto de los que vivían en El Salvador se mantiene

6. PNUD, Informe sobre Desarrollo Humano 2009. Superando barreras: Movilidad y desarrollo humanos, Grupo Mundi-Prensa, Madrid, Barcelona, México, 2009, pp. 209-212.

7. PNUD, Informe sobre Desarrollo Humano 2009, op. cit., pp. 190-192; e Informe sobre Desarrollo Humano 1998, Mundi-Prensa, Madrid, Barcelona, México, 1998, pp. 146-147. 
prácticamente constante. Pero en 2008 vivían ya en los Estados Unidos 1,591,640 salvadoreños, según el Census Bureau American Community Survey, y en El Salvador 6,122,413, según la Dirección de Estadística y Censos, para una tasa de gente viviendo en Estados Unidos del 25.99\% de los que vivían en El Salvador ${ }^{8}$. El salto hacia adelante es impresionante. En términos de su importancia económica, los datos nos dan que en 1989 los salvadoreños en Estados Unidos enviaron 327 millones de dólares en remesas, o el 6.6\% del PIB. Pero en 2008, antes de que se hiciera marcar el descenso por efecto de la primera gran crisis de la globalización, los salvadoreños enviaron 3 mil 787 millones y medio de dólares, o el 17.1\% del PIB. Las circunstancias de la guerra, de la pobreza y, sobre todo, del bloqueo del ascenso socioeconómico han hecho que la exportación de personas trabajadoras se haya convertido en la más importante del país. Con el costo humano de dolor y sacrificio que esto ha representado.

Así pues, el retraso en los procesos de reconciliación tiene que ver también con la gran desigualdad imperante en el país, con el alto porcentaje de pobreza humana y con la grande y creciente corriente migratoria hacia los Estados Unidos. Tiene que ver, en último término, con una "civilización del capital", que privilegia desmesurada e inequitativamente al capital por encima del trabajo, y con una "civilización de la riqueza"10, que supervalora el enriquecimiento insaciable de pocos e infravalora la pobreza permanente de muchos. No es extraño que este tipo de civilización, opuesta al bienestar propio de la paz, produzca resentimiento y aleje de la reconciliación. El lema de la celebración del aniversario de los mártires este año reza así: "Solo utópica y esperanzadamente podemos tener ánimos para intentar con los pobres y oprimidos del mundo revertir la historia"11. Son palabras del antiguo rector de la UCA, Ignacio Ellacuría, pocos días antes de ser asesinado con sus compañeros jesuitas y las dos mujeres que esa noche paradójicamente se refugiaron en su casa.

Revertir la historia significa imprimirle otra dirección, una dirección que la haga caminar hacia el acercamiento del cumplimiento de la esperanza de los pobres (Sal 9, 19). En este país los Acuerdos de Paz hicieron surgir una poderosa corriente de esperanza en las mayorías. Esa esperanza podría ser bien interpretada con las palabras del libro profético que lleva el nombre de Isaías:

8. L. C. Ruiz, El Salvador 1989-2009. Estudios sobre migraciones y salvadoreños en Estados Unidos desde las categorías de Segundo Montes, San Salvador, Universidad Centroamericana "José Simeón Cañas", PNUD Desarrollo Humano y Migraciones, 2011, p. 12.

9. Ibid., pp. 76-77.

10. I. Ellacuría, "El desafío de las mayorías populares", en Escritos universitarios, San Salvador, UCA Editores, 1999, pp. 300-301 y 305.

11. Ibid., p. 301. 
Miren, yo voy a crear un cielo nuevo y una tierra nueva; de lo pasado no quedará recuerdo ni se lo traerá a la memoria, más bien gócense y alégrense siempre por lo que voy a crear; miren, voy a transformar a Jerusalén en alegría y a su población en gozo (...); ya no habrá allí niños que mueran al nacer ni adultos que no completen sus años (...) Construirán casas y las habitarán; plantarán viñas y comerán sus frutos, no construirán para que otro habite, ni plantarán para que otro coma (...) No se fatigarán en vano, no engendrarán hijos para la catástrofe. (Is 65, 17-23.)

¡En este país aún se engendran hijos para la catástrofe! Casi todos los años la vulnerabilidad natural se multiplica por la vulnerabilidad ecológica y la vulnerabilidad social y política, y los huracanes o las tormentas tropicales o los terremotos hacen que mucha gente se haya fatigado en vano, porque el Estado es débil, porque los ricos no pagan impuestos correspondientes a su riqueza, y el Estado, en consecuencia, carece de medios para dragar el río Lempa, para rellenar y nivelar las cárcavas, para reconstruir los puentes, para edificar contrafuertes en los taludes que bordean las carreteras, para reedificar los centros de salud y las escuelas derruidas, y para importar los granos necesarios para poder competir en los mercados con los especuladores privados. La carga tributaria era, en la última década del siglo XX, de $12 \%$ del PIB, mientras que era de $19 \%$ en los Estados Unidos, de $20 \%$ en Chile, de $21 \%$ en Panamá, de $22 \%$ en Costa Rica, de $24 \%$ en Nicaragua, de $28 \%$ en Uruguay, sin hablar de Suecia (33\%), Reino Unido (34\%), Dinamarca y Alemania (35\%), Francia (38\%), y Holanda y Croacia $(43 \%)^{12}$. Y ni en Chile ni en Costa Rica o Nicaragua, ni por supuesto en Francia u Holanda se oye hablar de que los inversionistas nacionales, agobiados por la carga fiscal, huyan de su país en estampida de capitales.

\section{No el frío olvido egoísta, sino el cálido recuerdo compasivo del sufrimiento, es el camino al perdón}

Es preciso abandonar el tremendo equívoco escondido en la frase "perdón y olvido". Hay que dar un fuerte desmentido al olvido como camino al perdón. El verdadero camino al perdón y, por él, a la reconciliación, es el recuerdo, la memoria histórica del corazón. Hay dos clases de recuerdo o memoria.

6.1. Una memoria basada en el resentimiento y la venganza. No es esta una memoria sanadora de las ofensas. En el Salmo 137 tenemos un ejemplo sobresaliente e impactante de este tipo de memoria. Parece que lo cantaban los israelitas deportados de su patria o los que, ya retornados, recordaban el tiempo del exilio:

¡Cómo cantar un canto del Señor

en tierra extranjera!

12. PNUD, Informe sobre Desarrollo Humano 1998, op. cit., pp. 182-183 y 204. 
Si me olvido de ti, Jerusalén,

que se me paralice la mano derecha,

que se me pegue la lengua al paladar

si no me acuerdo de ti,

si no exalto a Jerusalén

como colmo de mi alegría.

Así se celebra el triunfo de la nostalgia patria. Pero el salmo no termina ahí. Los exiliados profieren una "bienaventuranza sarcástica"13 que alcanza en el corazón a los que han sido causa de su desgracia. El horizonte está, pues, cargado de deseos de venganza:

¡Capital de Babilonia, destructora,

dichoso el que te pague

el mal que nos has hecho!

¡Dichoso el que agarre y estrelle

a tus hijos contra la peña!

El deseo de venganza, sin dejar de ser histórico, es un recuerdo podrido, es la base del resentimiento en las víctimas y puede llegar a transformar el deseo de liberación en odio o en eterna victimización. Y el deseo de venganza engendra, además, violencia; una nueva violencia. Por ejemplo, en el país, la violencia de las pandillas juveniles, llamadas "maras", o "la mara 18" y "la mara 13". ¿Qué significan estos números? Es bien sabido: son las calles de Los Ángeles, en California, donde los adolescentes y los jóvenes exiliados y emigrantes durante la guerra en El Salvador encontraron una pertenencia que los rescataba de la soledad familiar producida por el trabajo a destajo de sus padres y de la pérdida de la escolaridad por la dificultad de la lengua, y donde reprodujeron, a la vez, con su violenta rivalidad, el conflicto armado que desgarraba a su país. Retornados luego muchos de ellos, es decir, sometidos a una nueva deportación por sus fechorías juveniles, mantuvieron en los barrios marginados y en los cantones rurales tanto la violencia como la rivalidad. Y los que habían quedado sin emigrar reprodujeron la estructura de las maras por la vía de la intercomunicación.

Sin embargo, es fácil y simplista responder al problema de las maras con el mismo resentimiento y un deseo de justicia, que en realidad es de venganza social. Un gran jesuita fallecido en 2006, el P. Manolo Maquieira, enfrentó este problema en un barrio marginado infestado de maras en Guatemala, llamado el Puente de Belize. Creó un proyecto educativo-laboral que otros jesuitas continúan hoy. Su visión de este tipo de marginación y de la violencia inherente a ella tiene rasgos profundamente sabios. Lo cito textualmente:

13. Así comenta La Biblia de nuestro pueblo, Bilbao, Mensajero, 2007, p. 1479. 
El barranco ${ }^{14}$ es otro "sacramento" muchas veces. Hay dos mundos, el mundo de los de arriba y el mundo de los de abajo. Me da la impresión que la gente casi no echa de menos los servicios básicos a veces, porque tienen un concepto de sí mismos tan bajo que creen que esos servicios básicos son para gente de dinero, son para los de arriba, no son para los del barranco. Los del barranco somos el submundo este en el que no tenemos ni derecho a nada y lo mejor que podemos hacer es morirnos. La pregunta siempre es por qué los jóvenes de aquí no tienen capacidad de crítica social o ni siquiera de envidia social, no van a pelearse con los jóvenes ricos, no van a pelearse a la salida de los colegios con los jóvenes de un colegio de pago. No. Se pelean entre ellos. Estamos en lo de siempre: "Basura contra basura". Es el sentimiento de que cada vez que un joven nuestro mata, yo creo que en el fondo se está suicidando. Es como estar viendo a la gente (...), como no tenemos nada que perder, ni tenemos nada, no me importa que esta gente se muera.

El P. Maquieira da una visión profunda y trágica del ingreso a las maras:

Es una salida para la propia impotencia; el hombre no querido y, además, que sabe que no va a ser querido nunca y que se va sintiendo incapaz de querer, por lo menos para salvar (...) algo de lo que lleva dentro, busca ser temido, por lo menos ser temido. Y luego, busca el grupo. Entonces la violencia por un lado es muy grupal y la violencia también da fuerza, da poder para el desposeído que es incapaz de buscar poder por otro sitio, pues lo encuentra (...) sobre todo en el grupo violento: causa miedo y eso le hace sentirse alguien, yo creo, individualmente pero sobre todo como grupo (...), esa pertenencia al grupo sustituye la falta de identidad que tiene él.

Pero esa identidad es falsa, piensa Maquieira:

Hay [bastantes] jóvenes con unos destrozos personales por falta de experiencia de amor, porque llegan a la adolescencia sin haberse sentido queridos profundamente nunca (...) sin seguridad, sin una figura paterna que tendría que darles seguridad en el futuro; porque llegan como sin identidad y demasiado abiertos a que sea un grupo el que les dé la identidad que no tienen; como no hay identidad, se sustituye por una pertenencia a algo, que por ser malo como es el caso de las maras, le acaba quitando más todavía la identidad, en vez de devolvérsela. ${ }^{15}$

14. En Ciudad de Guatemala, los barrios marginados están no pocas veces en barrancos invisibles o invisibilizados.

15. Las tres citas son de G. Vásquez, "Manolo Maquieira: un sueño, un proyecto que abre futuro a los jóvenes urbano-marginales", Amigos de Jesús, testigos del Reino de Dios, año XXXI, n. ${ }^{\circ} 124$, octubre-diciembre de 2007, pp. 66, 65-66 y 63-64. 
6.2. Frente a esta memoria de pudrición de sueños e identidad contaminada, vista, sin embargo, con compasión y con un proyecto para rescatarla de su desgracia, y no con el único deseo de exterminarla, hay otra memoria en la Biblia cristiana que recuerda que la vida vale la pena solo cuando la memoria de la opresión y de la injusticia conduce a la entrega de la vida sin fundamentarse en el odio, sino fundándose en el amor, un amor simbolizado en la mesa compartida, que hace realidad la promesa de igualdad del pasado - "No habrá pobres entre los tuyos" (Dt 15, 4-11) - y compromete fraternalmente la libertad hacia el presente y el futuro - "Hagan esto en memoria mía" (Lc 22, 19)—. El Evangelio de Lucas lo narra así: "Cuando llegó la hora, se puso a la mesa con los Apóstoles y les dijo: 'Cuánto he deseado comer con ustedes esta Pascua antes de mi pasión. Les aseguro que no volveré a comerla hasta que alcance su cumplimiento en el Reino de Dios"'.

Jesús de Nazaret, pues, en la hora en que se da cuenta claramente de que lo van a asesinar, no renuncia al sueño de su Padre, el reino que ha sido el proyecto de su vida. Y deja este sueño y este proyecto del reino en herencia a sus seguidores. Lucas continúa:

Tomando pan, dio gracias, lo partió y se los dio diciendo:

"Esto es mi cuerpo que se entrega por ustedes.

Hagan esto en memoria mía".

Igualmente, tomó la copa después de cenar y dijo:

"Esta es la copa de la nueva alianza, sellada con mi sangre, que se derrama por ustedes". (Lc 22, 14-16.19-20.)

Se trata de una memoria que deberá recordarse en una convivencia de emulación por el fraterno servicio mutuo de compañeros y no en la lucha por el poder disfrazado por la ideología de la beneficencia. Lucas lo expresa así:

Luego, surgió una disputa entre ellos sobre quién de ellos se consideraba el más importante.

Jesús les dijo:

"Los reyes de los paganos los tienen sometidos y los que imponen su autoridad se hacen llamar benefactores.

Ustedes no sean así; al contrario...". [Estén a la mesa como quien sirve, como yo estoy en medio de ustedes sirviendo.] (Lc 22, 24-27.)

¿Cómo es posible compartir semanalmente esta memoria en la misa dominical y continuar manteniendo el corazón endurecido frente a la pobreza que deshumaniza a las multitudes?

\section{La reconciliación con Dios y entre nosotros, y su historización en El Salvador}

Lo que la memoria histórica nos ha enseñado, en cambio, desde la experiencia de Centroamérica —nos lo podría haber enseñado también desde Somalia o 
Ruanda o Filipinas, p. ej., o desde el contacto con los heroinómanos sin empleo del Bronx, como se lo enseñó primordialmente a Dean Brackley antes de que viniera a El Salvador-, es que los cristianos podemos aportar a la lucha por la justicia y al combate por el reino de la igualdad y de la libertad, una cosa muy humilde que se llama el servicio mutuo con amor: "En todo amar y servir", diría Ignacio de Loyola $^{16}$. Eso es lo que nos dejaron como ejemplo los mártires centroamericanos Rutilio Grande, Óscar Arnulfo Romero, Ignacio Ellacuría y sus compañeros, Julia Elba y Celina, y una gran multitud de testigos de la fe y la esperanza que dieron su cuerpo y su sangre con amor para buscar la justicia y la paz. Hoy debemos continuarlo con el servicio, lleno de amor, al proceso de reconciliación.

7.1. ¿Qué significa cristianamente la reconciliación? ¿Cuál es su comprensión (intellectus reconciliationis)? Tiene que ver con un cambio profundo, con una conversión que nos hace llegar a ser una "nueva criatura", es decir, una persona renovada y novedosa, en medio de este mundo ambiguo y muchas veces directamente perverso, que fomenta la hostilidad y la enemistad, a través de la lucha por la mayor competencia, la mayor ganancia y el mayor consumo. También los autores del informe de la Comisión de la Verdad querían una "paz nueva". Lo novedoso de esa paz era que estuviera "fundada, levantada, edificada sobre la transparencia" de la verdad de lo ocurrido en la guerra, "para que esa verdad no sea instrumento dócil de impunidad sino de justicia". Lo novedoso de las personas y del mundo cristianamente recreado es precisamente que convivan reconciliadas. Así lo expresa la fe cristiana y lo teologiza san Pablo. Para ello es preciso que Dios cree en nosotros "un corazón puro" y que nosotros ofrezcamos "un espíritu quebrantado, un corazón arrepentido y humillado" (Sal 51, 12 y 19). Nosotros, dice san Pablo, somos servidores de la reconciliación y Dios nos ha confiado este mensaje. Tanto en la historia previa a la guerra en el país, historia de explotación y represión, como en la historia misma de la guerra, y en la historia posterior, cuando se reprivatizaron los bancos ofreciéndolos a precios de quiebra a las familias poderosas del país, ha habido gravísimas mentiras y deshumanizaciones - injusticias homicidas- que teológicamente han de ser conocidas como "pecado del mundo" (Jn 1, 29), "pecado social"17, "violencia institucionalizada"18, y como efecto de ellas el pueblo ha sido la víctima principal.

Teológicamente, la reconciliación es en primer lugar obra de Dios, el único que perdona los pecados (Mc 2, 1-11) y quita el pecado del mundo (Jn 1, 29). Pero ¿cómo nos ha reconciliado Dios? Gracias a su vida humana en medio de nosotros, a la vida de Jesús de Nazaret, su hijo, y en especial a su lucha contra el pecado del mundo y a su ejecución en el patíbulo de la cruz como blasfemo

16. Ejercicios Espirituales, n. ${ }^{\circ} 233$.

17. Puebla. Comunión y participación, Madrid, BAC, 1982, 2599 (28), p. 432.

18. Medellín. La Iglesia en la actual transformación de América Latina a la luz del Concilio, Bogotá, Secretariado General del CELAM, 1969, 2, 16, p. 72. 
(Mc 15, 63-64) y agitador (Lc 23, 1-5), mientras ponía su suerte y su vida en manos del Padre (Lc 23, 46). Es el modo preciso y concreto de vivir y morir de Jesús de Nazaret, de vivir y entregar la vida, el que se ha vuelto medio de reconciliación entre nosotros, el mundo y Dios. Esta tremenda figura del Hijo y del hombre por antonomasia (Jn 19,5), Jesús de Nazaret, tratado por los poderes de este mundo como un delincuente peligroso y como un pecador ejecutado en la cruz, es la vida y la muerte por medio de la cual Dios nos ha reconciliado. Pero hace falta que nosotros, en el corazón y también en el mundo con sus estructuras, nos dejemos reconciliar con Dios.

Leamos ahora el trozo concreto de Pablo que nos anuncia la buena noticia de nuestra reconciliación:

Si uno es cristiano, es criatura nueva. Lo antiguo pasó, ha llegado lo nuevo. Y todo es obra de Dios, que nos reconcilió consigo por medio de Cristo y nos encomendó el ministerio de la reconciliación. Es decir, Dios estaba, por medio de Cristo, reconciliando el mundo consigo, no apuntándole los delitos, y nos confió el mensaje de la reconciliación. Somos embajadores de Cristo y es como si Dios hablase por nosotros. Por Cristo les suplicamos: déjense reconciliar con Dios. Al que no supo de pecado, por nosotros lo trató como pecador, para que nosotros, por su medio, fuéramos inocentes ante Dios. (2 Cor 5, 17-21.)

Es necesario historizar esto hoy. Y creo que lo debemos hacer así: "Dios estaba, por medio del pueblo crucificado de El Salvador, y por medio de todos los pueblos crucificados de la historia, reconciliando el mundo consigo, no apuntándole los delitos".

7.2. En virtud de la hermandad auténtica y solidaria de Jesús de Nazaret con todos los crucificados de la historia, son estos los protagonistas auténticos de la reconciliación, son la presencia por la que Dios nos reconcilia. En los crucificados del país y de la historia, Jesús de Nazaret, el Cristo, está presente y por eso afirma el Evangelio de Mateo que "todo lo que se hace a ellos se le hace a Jesús mismo", y todo lo bueno que se omite hacer a los crucificados de este mundo se omite hacer al mismo Jesús (Mt 25, 34-45). No es "como si" se hiciera a Jesucristo o "como si" se dejara de hacer con él, sino que se hace o se deja de hacer realmente a Jesucristo. Esta manera de ver las cosas en el Evangelio fundamenta evidentemente la obligación de ser compasivamente solidarios con los hambrientos y todos los que sufren otras injusticias semejantes, que injusticias son, hablando con honradez, y no solo desgracias.

Por eso el obispo Pedro Casaldáliga se ha atrevido a decir que en la vida y en la historia hay dos absolutos: "Dios y el hambre". En el mundo de hoy —ha dicho Jean Ziegler, relator de la ONU contra el hambre- "un niño que muere 
de hambre, muere asesinado"19. Por eso también la consideración teórica del sufrimiento humano o la ausencia por ignorancia u ocultamiento teóricos califican dos tipos de economía: la economía personal y globalmente solidaria y la economía del capitalismo globalmente salvaje. Si se lee, por ejemplo, a un economista como Paul Krugman, premio Nobel, se puede ver cómo termina su reciente comentario sobre los acuerdos a los que los líderes de la Unión Europea llegaron el 26 de octubre de este año (2011), en Bruselas, y los compara con el modo de actuar diferente de los líderes en Islandia:

Aquí hay una gran lección para los demás entre nosotros: el sufrimiento que tantos de nuestros ciudadanos están afrontando es innecesario. Si esta es una época de increíble sufrimiento y si vivimos en una sociedad mucho más dura, eso ha sido una opción. No tenía y no tiene por qué ser así. ${ }^{20}$

Se puede leer, por el contrario, el editorial de El Diario de Hoy del 28 de octubre de 2011. Su título es "Promuevan inversiones para reconstruir daños". No hay en este editorial una sola consideración del sufrimiento que esos daños han causado. Se propone para la reconstrucción la misma receta que para cualquier otro tipo de producción, eso sí "con el menor número de (...) impuestos". Y que sea la empresa privada únicamente la que reconstruya, porque no existen "reconstructólogos".

Hasta aquí estamos acostumbrados tal vez a ver así las cosas cristianamente: en los pobres, en los humillados y ofendidos, nos encontramos con Jesús.

7.3. Pero la historización de la reconciliación no significa únicamente el ejercicio de la fraternidad jesuánica con las víctimas de la historia. Significa además que estas víctimas, "el pueblo crucificado", es, junto con el Señor crucificado, el medio por el que Dios reconcilia al mundo. Son ellos, los crucificados con espíritu, los que toman a veces la iniciativa de "perdonar lo imperdonable" y de hacer una "opción fundamental por el enemigo", como escuché del teólogo jesuita Xavier Melloni, hablando de la tesis que defendería en Lovaina otro jesuita que había trabajado con ruandeses en los campos de refugiados de los Grandes Lagos, en el corazón de África. Los crucificados de la historia y los crucificados aquí en El Salvador son, como pensaba Ignacio Ellacuría, "el signo de los tiempos principal" en cada época ${ }^{21}$, al igual que el Crucificado del Gólgota fue el "signo de los tiempos" privilegiado para los primeros cristianos (Hch 2, 23 y 32) y lo sigue siendo para nosotros a un nivel análogo de trascendencia. Como Jesús crucificado fue "escándalo para los judíos y locura para los griegos" (1 Cor 1, 23),

19. R. Carrizo Couto, "Entrevista: Jean Ziegler, relator de la ONU para la Alimentación", El País, 9 de mayo de 2005, p. 40.

20. P. Krugman, “The path not taken”, The New York Times, 27 de octubre de 2011.

21. I. Ellacuría, "Discernir el 'signo' de los tiempos", en Escritos teológicos, II, San Salvador, UCA Editores, 2000, p. 134. 
los crucificados en El Salvador y en el mundo son escándalo para el capital y locura para su riqueza, pero en ellos está escondida "la fuerza y la sabiduría de Dios" (1 Cor 1, 24). Han sido tratados por el mundo como si fueran miserables, haraganes, borrachos, subversivos, en una palabra, como si fueran pecadores (cfr. 2 Cor 5, 21) y malditos (cfr. Gal 3, 13), como fue tratado Jesús por los ricos y poderosos de su tiempo; pero en ellos, que son hermanos de Jesús de Nazaret (Hbr 2, 11), encontramos muchas veces la iniciativa de la reconciliación y la construcción de los puentes que necesitamos para encontrarnos como hermanos sobre el río de esta vida socialmente tan revuelta, injusta y violenta. En su vida de trabajo, y de sobria y a veces atenazante y asfixiante austeridad, encontramos la inspiración para la reconciliación con nuestros hermanos de humanidad y con nuestra hermana la tierra. Escuchemos más pronto que tarde la exhortación, el clamor que se alza tumultuoso desde su vida crucificada: “¡Déjense reconciliar con Dios! ¡Dejémonos reconciliar entre nosotros!”22.

No se trata, pues, de "perdón y olvido". Se trata de recuerdo y perdón. Para que no vuelva todo lo que se olvida en una especie de horrible y eterno retorno. Para que no se vuelvan a cometer los mismos crímenes por causa de su olvido. Se trata de un recuerdo que pone también las cosas en su lugar, que rompe la misma ambigüedad de la memoria. Porque la memoria puede también tergiversar el corazón y endurecerlo: es lo que está pasando con no pocos israelíes, víctimas de la shoah, frente a los palestinos, aunque no con todos los israelíes; solo con aquellos que además de haber sido víctimas o herederos de las víctimas absolutizan su victimización, sin dejar que la memoria de la catástrofe se vuelva recuerdo, memoria histórica que vuelva fraterno al corazón. No se trata de soslayar que, en palabras del poeta español José Ángel Valente (1929-2000), "de cuantos reinos tiene el hombre, el más oscuro es el recuerdo".

De esta oscuridad del recuerdo, cuando solo se queda en memoria y no recrea el sufrimiento en un corazón quebrantado y la crucifixión en una esperanza de resurrección, nos liberan Jesús de Nazaret, nuestro Dios crucificado, y los pueblos crucificados del mundo, aquí y hoy el pueblo crucificado de El Salvador, que perdonan a los que supieron lo que hacían y a los que no lo supieron ( $c f r$. Lc 23, 34), y en ese modo humanizante de vivir y morir reciben el reconocimiento del mundo que cree en su resurrección: "Verdaderamente, estas personas eran hijas de Dios". Porque solo la crucifixión de nuestros pueblos no trae salvación ni otro mundo posible. Solo su crucifixión con su resurrección trae salvación en la historia. Por eso, delante de Jesús crucificado, en los Ejercicios, Ignacio Ellacuría incitaba a preguntar: "¿Qué he hecho yo para bajar de la cruz a mis hermanos crucificados? ¿Qué hago yo hoy? Y ¿qué he de hacer como proyecto de

22. Obviamente, me he inspirado en I. Ellacuría, "El pueblo crucificado", en I. Ellacuría y J. Sobrino, Mysterium liberationis, II, Madrid, Trotta, 1990, pp. 189-216. 
vida para bajar de la cruz fraternalmente a las personas crucificadas y ayudarlas solidariamente a ponerse en camino de resurrección?". Al practicar así el amor eficaz esperanzado, nos adentraremos en el camino hacia la verdad que libera, la justicia que restaura, la superación de la impunidad y la reconciliación en la paz que hace vivir con dignidad y bienestar.

No podemos olvidar el comienzo de la primera carta de Pablo a los corintios: "Nosotros anunciamos un Cristo - es decir un Mesías - crucificado, escándalo para los judíos, locura para los paganos, pero para los llamados (...), un Cristo que es fuerza y sabiduría de Dios" (1 Cor 1, 23-24). Como solo por medio de Jesús crucificado nos reconcilió Dios consigo mismo, solo por medio del pueblo crucificado de El Salvador, imagen histórica real de Jesús crucificado, nos irá reconciliando en el país para que aquella reconciliación cristológica se prolongue en reconciliación hoy en la historia. Tampoco podemos olvidar el final de la misma primera carta a los corintios: "Cristo ha resucitado de entre los muertos (...), el primero de los que han muerto" (1 Cor 15, 20). "No hay salvación por el mero hecho de la resurrección y de la muerte: solo un pueblo que vive, porque ha resucitado de la muerte que se le ha infligido, es el que puede salvar al mundo" 23 . Precisamente por esta fe, es necesario reconocer la verdad de la crucifixión de este pueblo, y también tratar de irlo bajando hoy fraternalmente de sus cruces y dejar que los crucificados con espíritu nos aporten, desde su resurrección, ya en esta historia y más allá de ella, un corazón nuevo a través de su propio corazón traspasado por el hambre y la inundación, por la desigualdad, la pobreza y la migración, pero tenso hacia la esperanza responsable y organizada en comunidades multiformes de solidaridad. Y así, también nos aportarán su deseo de estructuras nuevas que hagan acercarse en medio de nosotros, en esta tierra, señales del reino (Lc 17, 21), es decir, inicios fehacientes de ese otro mundo posible que Jesús mostró cuando "pasó haciendo el bien y librando a todos los poseídos por el mal” (Hch 10, 38).

23. Ibid., p. 215. 